\title{
What Makes the Service Satisfactory? Simulation-Based Approach In
} Data Generation

Görkem Sarıyer, Çağrı Bulut

Yasar University, Business Administration Department, Izmir, Turkey

gorkem.ataman@yasar.edu.tr

Yasar University, Business Administration Department, Izmir, Turkey

\section{ABSTRACT}

cagri.bulut@yasar.edu.tr

Increasing customer satisfaction, or satisfying customers' needs and aspirations are the primary concern of the service industry. The proposed work defines the customer satisfaction via a utility function depending on the variables of service quality, perceived value of the service, and word-of-mouth. As an innovative approach, simulation techniques are used to obtain data of these variables instead of survey techniques.

\section{Indexing terms/Keywords}

Simulation; Service Quality; Customer Satisfaction; Perceived Service Value; Word-of-mouth

\section{Academic Discipline And Sub-Disciplines}

Business Studies, Social Science

\section{SUBJECT CLASSIFICATION}

Service Industry, Marketing, Customer Behaviour

\section{TYPE (METHOD/APPROACH)}

Simulation, Survey

\section{Council for Innovative Research}

Peer Review Research Publishing System

\section{Journal: Journal of Social Sciences Research}

Vol. 5, No. 2

Jssreditor.cir@gmail.com 


\section{INTRODUCTION}

Service choice is a strategical decision since a customer chooses the service provider among a bunch of competitiors in a given service industry. While choosing between these competitors, he considers his self satisfaction. Thus, increasing customer satisfaction levels, or satisfying customers' needs and aspirations are the primary concern of the service industry.

McDougall and Levesque [14] used the customer satisfaction as the overall assessment of the service provider while future intentions are most likely to return the service provider. The customer satisfaction is defined and measured using different scales by in literature. Cronin and Taylor [8] used a one-item scale asking for the overall feeling of the customer. Bitner and Hubbert [4] used four-items to evaluate the overall satisfaction of the customer of the service he received. Price et. al. [18] used six-item scale to measure service satisfaction, as well as modelling the relationships among performance of the service provider, service satisfaction and effective response rate. On the other hand, different variables affecting the customer satisfaction are explored in service literature. Most widely used explanatory variable is the service quality. Studies including Bitner [3], Fornell [9] and Cronin et. al. [7] showed that the service quality positively affect the consumer's behaviours or decisions. Hurley and Estelami [12] discussed the service quality and customer satisfaction as distinct variables, having a causal relationship; they showed that service quality affects customer satisfaction and this influences the future decisions of the customer regarding the service system.

Perceived value is the other used factor in explaining the customer satisfaction. Huber et. al. [11] defined the perceived value as a complicated concept depends on various biases and emphases. According to Bettman et. al. [2] it was the value perceived by the customers when they receive a service. Anderson and Srinivasan [1], Pura [19], Chen and Dubinsky [6] were used the perceived value as an indicator of buying decisions of customers.

Additionally, Kim et. al. [15] discussed that the customer satisfaction ensures positive word-of-mouth. Thus, positive wordof- mouth is the other factor which is correlated with the customer satisfaction. To sum up, using an empirical study Hu et. al. [10] modeled the relationship between service quality, perceived value, customer satisfaction and image, where image of the service is influenced by the others. In their survey they measured other variables such as reliability, responsiveness, assurance, empathy, behavioural intention, word-of-mouth, purchase intention and price sensitivity. Based on the proposed model, they concluded that providing high quality service and generating high customer value result in achieving high customer satisfaction. Bolton and Drew [5], Parasuraman et. al $[16,17]$ were some of the other papers which have indicated that service quality, customer perceived value, and customer satisfaction are the main factors increasing the competitive advantage within different service providers.

The proposed paper defines the utility function of a customer as a satisfaction level of the received service. The strategic decision of the customer is assumed dependent on his utility function where service quality, perceived value of the service and word-of-mouth are the main variables of this function. In order to obtain data for these variables a different methodology is used instead of the survey method. Data is generated using simulation in this paper. While in engineering and sciences, simulation is frequently used to imitate the real life operations and systems, its usage is rare in social sciences. Riley et. al. [20] showed how integrated business simulations can be used to enhance accounting education. Markovic and Plecic [13] listed the benefits of using visual software simulations in business education. However, using simulation for generating data is an innovative approach in social sciences.

In order to simulate data of the variables, the main characteristics of the variables, such as the distribution with parameters, are required to be known. The distribution parameters of the simulation, are taken from Hu et. al. [10]. Based on these expected value, and standard deviation statistics, data for the variables of service quality, perceived service value, and worth-of mouth are simulated. The relationship between these variables is analyzed and modeled, and finally the effect of changing distribution parameters in this relationship, and the utility function is discussed in this paper.

The organization of this paper is follows. In Section 2, real data statistics taken from the survey study is given and the simulation method is explained. In Section 3, different numerical expereriments and their results are given. In Section 4 , these numerical studies are discussed in detail. In Section 5, the conclusions and future research directions are given.

\section{METHODOLOGY}

To model the relationships and impacts of service quality, perceived value, customer satisfaction, and image, Hu. et. al. [10] collected a sample from an hotel industry and questionaired this sample. In the questionnaire they used the 7-point likert scale ( $1=$ not all likely, $7=$ extremely likely). Descriptive statistics including mean and standard deviation of each variable in the proposed model is presented in their paper (see Table 1).

Table 1: Descriptive statistics of variables

\begin{tabular}{|l|l|l|l|}
\hline Variable & Mean $(\mu)$ & Standard deviation $(\sigma)$ & $\mu / \sigma$ \\
\hline Customer satisfaction & 6.11 & 0.84 & 7.27 \\
\hline Service quality & 6.18 & 0.65 & 9.51 \\
\hline Perceived service value & 5.94 & 0.98 & 6.06 \\
\hline Word-of-mouth & 6.04 & 1.04 & 5,81 \\
\hline
\end{tabular}


Instead of a discrete scale, a continous scale is assumed to be use as a measure of customers' perceptions of the considered variables in this paper. In order to generate data of the variables which are listed in Table 1, the Normal Distribution assumption is used. Thus, the perceptions of the customers are assumed as continous and coming from the Normal Distribution with the given mean and standard deviation statistics in the fixed probability ranges. Probability range defines the minimum and maximum values of the probabilistic or the random function.

In Section 3, different numerical studies are given to show how the change in these statistics affect the relation between the variables and the regression model. First, assuming a fixed probability ranges for the variables, data is simulated using Table 1 values, correlation between variables and the model equation are listed. Then, for the same probability ranges, a small change is made on expected value or standard deviation of one variable. Data is simulated considering this change, correlations between variables and model equation are listed. Finally to show the effect of the probability range in the model, data is simulated using a different probability range and re-modeled.

\section{RESULTS}

\section{Experiment 1}

The model variables are assumed to follow a Normal Distribution with specified mean and standard deviation values given in Table 1. For the assumed fixed probability ranges of the variables see Table 2.

\section{Table 2: Assumed Probability Ranges of the Variables}

\begin{tabular}{|l|l|}
\hline Variable & Probability Range \\
\hline Customer satisfaction & $(0,1)$ \\
\hline Service quality & {$[0.60,0.70]$} \\
\hline Perceived service value & {$[0.45-0.55]$} \\
\hline
\end{tabular}

Customer satisfaction level is specifically assumed in whole probability range, since it can depend on other factors than listed and can be any.

The notations used for the variables can be listed as:

$$
\begin{aligned}
& Y: \text { customer satisfaction } \\
& X_{1} \text { : service quality } \\
& X_{2}: \text { perceived service value } \\
& X_{3} \text { : word of mouth }
\end{aligned}
$$

By using Table 1 and Table 2 values, 1000 data is simulated for each of the variable.

The correlation between customer satisfaction and service quality, perceived service value, word-of-mouth and the regression model coefficients are summarized in Table 3.

Table 3: Summary Results of Experiment 1

\begin{tabular}{|l|l|}
\hline Correlation values & Model Summary \\
\hline$Y-X_{1}: 0.963$ & Model coefficient $\left(X_{1}\right): 28544$ \\
$Y-X_{2}: 0.962$ & Model coefficient $\left(X_{2}\right): 11912$ \\
$Y-X_{3}: 0.963$ & Model coefficient $\left(X_{3}\right):-29472$ \\
& Model constant: -68520 \\
& R-sq (adjusted): $97.5 \%$ \\
\hline
\end{tabular}

\section{Experiment 2}

All the values of Table 1 and Table 2 are kept the same, except the descriptive statistics of the variable service quality $\left(X_{1}\right)$ . Mean and standard deviation values of $X_{1}$ are respectively assumed as 18,54 and 1,95

(keeping the $\mu / \sigma$ ratio as 9.51 ).

Table 4: Summary Results of Experiment 2

\begin{tabular}{|l|l|}
\hline Correlation values & Model Summary \\
\hline$Y-X_{1}: 0.963$ & Model coefficient $\left(X_{1}\right): 9518$ \\
$Y-X_{2}: 0.962$ & Model coefficient $\left(X_{2}\right): 11912$ \\
$Y-X_{3}: 0.963$ & Model coefficient $\left(X_{3}\right):-29472$ \\
\hline
\end{tabular}




\begin{tabular}{|l|l|}
\hline & Model constant: -68520 \\
R-sq (adjusted): $97.5 \%$
\end{tabular}

\section{Experiment 3}

All the values of Table 1 and Table 2 are kept the same, except the descriptive statistics of the variable word-of-mouth $\left(X_{3}\right)$. Mean and standard deviation values of $X_{2}$ are respectively assumed as 2.01 and 0.34 (keeping the $\mu / \sigma$ ratio as $5.81)$.

Table 5: Summary Results of Experiment 3

\begin{tabular}{|l|l|}
\hline Correlation values & Model Summary \\
\hline$Y-X_{1}: 0.963$ & Model coefficient $\left(X_{1}\right): 28544$ \\
$Y-X_{2}: 0.962$ & Model coefficient $\left(X_{2}\right): 11912$ \\
$Y-X_{3}: 0.963$ & Model coefficient $\left(X_{3}\right):-87575$ \\
& Model constant: -70507 \\
& R-sq (adjusted): $97.5 \%$ \\
\hline
\end{tabular}

\section{Experiment 4}

All the values of Table 1 and Table 2 are kept the same, except the descriptive statistics of the response variable, customer satisfaction $(Y$ ). Mean and standard deviation values of $Y$ are respectively assumed as 30.55 and 4.2 (keeping the $\mu / \sigma$ ratio as 5.81$)$.

\section{Table 6: Summary Results of Experiment 4}

\section{Experiment 5}

\begin{tabular}{|l|l|}
\hline Correlation values & Model Summary \\
\hline$Y-X_{1}: 0.963$ & Model coefficient $\left(X_{1}\right): 142718$ \\
$Y-X_{2}: 0.962$ & Model coefficient $\left(X_{2}\right): 59560$ \\
$Y-X_{3}: 0.963$ & Model coefficient $\left(X_{3}\right):-147362$ \\
& Model constant: -342601 \\
& R-sq (adjusted): $97.5 \%$ \\
\hline
\end{tabular}

All the values of Table 1 and Table 2 are kept the same, except the probability range of the variable perceived service value $\left(X_{2}\right)$. Probability range of $X_{2}$ is assumed as $[0.95,1)$.

Table 7: Summary Results of Experiment 5

\begin{tabular}{|l|l|}
\hline Correlation values & Model Summary \\
\hline$Y-X_{1}: 0.963$ & Model coefficient $\left(X_{1}\right):-547$ \\
$Y-X_{2}: 0.943$ & Model coefficient $\left(X_{2}\right): 1,46$ \\
$Y-X_{3}: 0.963$ & Model coefficient $\left(X_{3}\right): 361$ \\
& Model constant: 1235 \\
& R-sq (adjusted): $98.6 \%$ \\
\hline
\end{tabular}

\section{Experiment 6}

All the values of Table 1 and Table 2 are kept the same, except the probability range of the variable perceived service value $\left(X_{2}\right)$. Probability range of $X_{2}$ is assumed as $[0.25,0.75]$. 
Table 8: Summary Results of Experiment 6

\begin{tabular}{|l|l|}
\hline Correlation values & Model Summary \\
\hline$Y-X_{1}: 0.963$ & Model coefficient $\left(X_{1}\right): 532$ \\
$Y-X_{2}: 0.966$ & Model coefficient $\left(X_{2}\right): 26,2$ \\
$Y-X_{3}: 0.963$ & Model coefficient $\left(X_{3}\right):-461$ \\
& Model constant: -666 \\
& R-sq (adjusted): $97.6 \%$ \\
\hline
\end{tabular}

\section{DISCUSSION}

Comparison of the results of Experiment 2, Experiment 3 and Experiment 4, with the base Experiment, Experiment 1, yields the conclusion of, changing the mean and standard deviation statistics (keeping the ratio between them the same) of the variables does not make any differentiation between the correlation values of the variables. However, the comparison between Experiment 5, Experiment 6 and Experiment 1 shows that changing the probability range of a variable affects both of the correlation values and the regression model.

The difference between Experiment 1 and Experiment 2 is the increase in mean and standard deviation statistics of a predictor variable. This differentiation causes a decrease in the model coefficient of the related predictor. Contrarily, Experiment 3 differs from Experiment 1 since mean and standard deviation statistics of a predictor variable is decreased. Due to this change, the model coefficient of the considered predictor is increased.

In Experiment 4, descriptive statistics of the response variable are increased compared to statistics of Experiment 1 . Due to this change, model coefficeinets of all the predictor variables are increased.

When the probability range of a predictor is shrinked, the relation between this variable and the response variable is decreased (compare Experiment 1 and Experiment 5). On the other hand enlarging the probability range of a variable, is caused an increase in correlation value between this predictor variable and the response variables (compare Experiment 1 and Experiment 6).

\section{CONCLUSIONS}

Collecting sufficent data representing almost the whole population is an expensive, and time consuming task in social sciences. In generating data, this paper uses an innovative approach which facilitates researching on these area. The main conclusion of the proposed work is: By using the main characteristics, distribution family with its own descriptive parameters, more and more data can be easily generated. Additionally, since perceptions, ideas or decisions of the customers can take any values, a continous-scale measures be prefferred in surveys instead of the discrete scale measures, so that fitting a distribution gets easier.

\section{REFERENCES}

[1] Anderson, R.E., Srinivasan, S.S. (2003). e-Satisfaction and e-loyalty: A contingency framework. Psychology \& Marketing, 20(2), 123-138

[2] Bettman, J., Luce, M., Payne, J. (1998). Constructive consumer choice process. Journal of Consumer Research, 25(3), 187-217

[3] Bitner, M.J. (1990). Evaluating service encounters: The effects of physical surroundings and employee responses. Journal of Marketing, 54(4), 69-82

[4] Bitner, M.J., Hubbert, A.R. (1994). Encounter satisfaction versus overall satisfaction versus quality. In R. Rust \& R. Oliver (Eds.) Service quality: New directions in theory and practice (pp. 72-94) Thousand Oaks, CA:Sage

[5] Bolton, R., Drew, J. (1991). A multistage model of customer's assessments of service quality and value. Journal of Consumer Research, 17(4), 375-384.

[6] Chen, Z., Dubinsky, A.J. (2003). A conceptual model of perceived customer value in e-commerce: A preliminary investigation. Psychology \& Marketing, 20(4), 323-347

[7] Cronin, J.J., Brady, M.K., Hult, G.T. (2000). Assessing the effects of quality, value and customer satisfaction on consumer behavioural intentions on service environments. Journal of Retailing, 76(2), 193-218

[8] Cronin, J.J., Taylor, S.A. (1992). Measuring service quality: A re-examination and extension. Journal of Marketing, 56(3), 55-68

[9] Fornell, C. (1992). A national customer satisfaction barometer: The Swedish experience. Journal of Marketing, 56(1), 6-21

[10] Hsin-Hui Hu, Jay Kandampully, Thanika Devi Juwaheer (2009), Relationships and impacts of the service quality, perceived value, customer satisfaction, and image: an empirical study. The Service Industries Journal, 29(2), 111-125 
[11] Huber, F., Hermann, A., Morgan, R.E. (2001). Gaining competitive advantage through customer value oriented management. Journal of Consumer Marketing, 18(1), 41-53

[12] Hurley, R.H., Estelami, H. (1998). Alternative indices for monitoring customer perceptions of service quality: A comparative evaluation in retail context. Journal of the Academy of Marketing Science, 26(3), 201-221

[13] Markovic, M., Plecic, K. (2013). Software simulation usage in business decision making education. Case Study, JITA, 3(1), 51-56

[14] McDougall, G., Levesque, T. (2000). Customer satisfaction with services: Putting perceived value into the equation. Journal of Services Marketing, 14(5), 392-410

[15] Kim, W.G., Lee, Y.K., Yoo, Y.J. (2006). Predictors of relationship quality and relationship outcomes in luxury restaurants. Journal of Hospitality \& Tourism Research, 30(2), 143-169

[16] Parasuraman, A., Berry, L.L., Zeithalm, V.A. (1991). Refinement and reassessment of the SEVQUAL scale. Journal of Retailing, 67(4), 420-450

[17] Parasuraman, A., Zeithalm, V.A., Berry, L.L. (1988). SERVQUAL: A multiple-item scale for measuring consumer perceptions of service quality. Journal of Retailing, 64(1), 12-40

[18] Price, L.L., Arnould, E.J., Tierney, P. (1995). Going to extremes: Managging service encountersand assessing provider performance. Journal of Marketing, 59(2), 83-97

[19] Pura, M. (2005). Linking perceived value and loyalty in location-based mobile services. Managing Service Quality, 15(6), 509-538

[20] Riley, R.A., Cadotte, E.R., Bonney, L., MacGuire, C. (2013). Using a business simulation to enhance accounting education. Issues In Accounting Education, 28(4), 801-822 